\title{
Эллипсометрический метод in situ расчёта профиля состава квантовых структур, выращиваемых на основе соединения $\mathrm{Hg}_{1-\mathrm{x}} \mathrm{Cd}_{\mathrm{x}} \mathrm{Te}$
}

\author{
В.А. Швец ${ }^{1,2)}$, С.А. Дворецкий ${ }^{1,3)}$, Н.Н. Михайлов ${ }^{1,2)}$, Д.Г Икусов ${ }^{1)}$,И.Н. Ужаков ${ }^{1)}$ \\ ${ }^{1}$ Институт физики полупроводников им. А.В. Ржсанова СО РАН, \\ Новосибирск, 630090, пр. Ак. Лаврентьева, 13 \\ ${ }^{2}$ Новосибирский государственный университет, 630090, г. Новосибирск, ул. Пирогова, 2 \\ ${ }^{3}$ Национальный исследовательский Томский государственный университет, 634050, Томск, \\ пр. Ленина, 36 \\ тел:+7 (383) 330-8716, факс: +7(383)333-27-71, эл.nочта: basil5353@mail.ru
}

DOI 10.34077/RCSP2019-110

Множественные квантовые ямы (КЯ) на основе соединения $\mathrm{Hg}_{1-\mathrm{x}} \mathrm{Cd}_{\mathrm{x}} \mathrm{Te}(\mathrm{KPT})$ - перспективные структуры для создания как излучающих устройств, так и фотоприемников среднего и дальнего (сверхдального) ИК диапазона. Для воспроизводимого выращивания КЯ с заданными оптическими свойствами необходим прецизионный контроль толщин слоев и распределения состава в них. В качестве такого метода контроля нами успешно используется одноволновая эллипсометрия ( $\lambda=632.8$ нм) in situ с высоким быстродействием. В наших предыдущих исследованиях было показано [1], что сравнение зависимости параметров $\Psi$ и $\Delta$, измеренной в процессе роста, с расчётной номограммой позволяет определять толщины слоёв и качественно характеризует изменение состава на границе широкозонного слоя и КЯ.

В продолжение этих исследований нами разработан и экспериментально реализован эллипсометрический метод расчёта профиля состава в таких структурах, основанный на разбиении исследуемого участка структуры на тонкие слои ( 0.5 нм) с последующим определением состава каждого такого слоя путём решения обратной задачи. Применяя метод эффективной подложки и используя измерения в начале и в конце роста слоя, удаётся определить его оптические постоянные и состав. Толщина слоя определялась по скорости его роста. Для этого перед началом выращивания структуры, в широкозонной обкладке создавалась ступенька состава $\left(\delta \mathrm{X}_{\mathrm{CdTe}} \leq 0,1\right)$, которая приводила к интерференционным колебаниям $\Psi, \Delta$ и позволяла провести прецизионную калибровку скорости роста.

C учётом малости толщин слоёв $\mathrm{d}_{\mathrm{i}}$, обратная задача решалась в приближении Друде. В результате разложения основного уравнения эллипсометрии по малому параметру $\mathrm{d}_{\mathrm{i}} / \lambda$ получается квадратное уравнение относительно комплексного показателя преломления і-го слоя. Это позволяет рассчитать состав аналитически, а не поисковыми методами, что повышает надёжность решения и делает возможным реализацию предложенного алгоритма в реальном времени. Численным моделированием установлено, что точность определения состава в области дна КЯ не хуже \pm 0.005 при пространственном разрешении 0.5 нм.

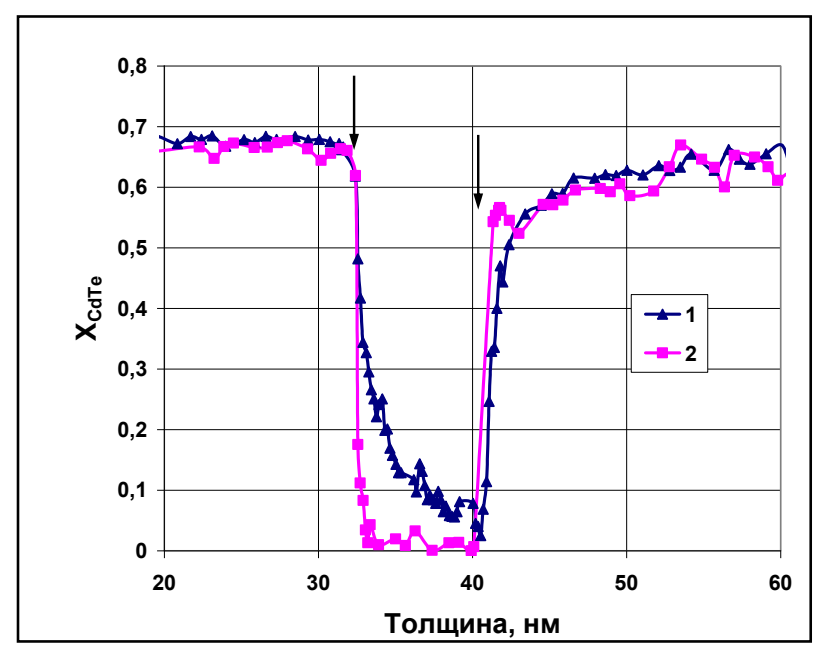

На рисунке показано распределение состава в отдельных КЯ практически одинаковой толщины для двух выращенных структур. Стрелками отмечены моменты открытия и закрытия заслонок. На рисунке хорошо видно, что для одной КЯ имеет место резкое, почти ступенчатое изменение состава, в то время как для другой - монотонное его изменение как при открытии, так и при закрытии заслонки. Эти отличия связаны с различными режимами работы источника потока кадмия.

Работа выполнена при частичной финансовой поддержке гранта РФФИ (проект №18-29-20053) и проекта №0306-2018-0010.

\section{Литература}

[1] Михайлов Н.Н. и др. Фотоника-2017. Тезисы докладов, Новосибирск, 2017, с. 62. 